\title{
A journal describing present undertakings, studies and labours of the ingenious
}

\author{
Peter Tyrer
}

\section{Summary}

A rationale for maintaining the existence of learned journals is put forward on the 343rd anniversary of the first such journal, the Philosophical Transactions of the Royal Society, and it is argued that the main aim of such journals has hardly changed since this time. The new-look British Journal of Psychiatry is intended to educate and instruct, and even entice readers from the functional and far less romantic online version.

\section{Declaration of interest}

P.T. is Editor of The British Journal of Psychiatry.
Peter Tyrer is Professor of Community Psychiatry at Imperial College, London and has been Editor of The British Journal of Psychiatry since 2003.

The New Year is the best time to introduce a new-look journal to our readers. We hope the changes we present are not seen merely as those of a follower of fashion and a need to change just because all around us are changing, but rather as an evolving process in making The British Journal of Psychiatry more interesting, more readable, more informative and, in a word, better. However, we have to justify such high-flown rhetoric with something approaching evidence and hope your feedback will help. Some of the changes may surprise you but they are the product of extensive deliberation and thought, and not taken lightly. They include a new cover, a change to two-colour text, a different typeface and column layout, adoption of the Vancouver reference style, more pictures and photographs and, in the words of our new Executive Contents Editor Robert Howard, more treats. Treats in this context I judge to be sections of the Journal that everyone wants to read - even though these might not have the sonorous impact of the original papers they are a little easier on the cortex than some of our other offerings.

\section{A little history}

In putting our work into context I would like to go back to the first learned journal in the English language, the Philosophical Transactions of the Royal Society, and the message heading its first volume in 1665; 'giving some accompt [sic] of the present undertakings, studies and labours of the ingenious in many considerable parts of the world'. ' Well, indeed. We could do much worse in The British Journal of Psychiatry in sticking to this message when we judge what to publish. It is worth reminding ourselves that the learned journal revolution initiated by the Philosophical Transactions is currently, after 343 years of expansion, in some danger of decline with the onset of 'open access', a process which paradoxically may lead to articles being read less rather than more. Some often forget that what you read in The British Journal of Psychiatry and other journals is a delicately fashioned product that owes much to the diligence of unsung scribes and editors. As Sampson has commented, 'Academics are experts on their subjects, but most are no better at writing clearly and unambiguously, or even avoiding spelling mistakes, than others tend to be these days. Before an academic manuscript gets into print it has to be polished, often heavily polished, to make it readable; but the research councils propose that authors will upload their own stuff into electronic "depositories", so the polishing will stop."

\section{Why we write and read}

My hope is that you will still read papers with pleasure on the printed page at least as much as you browse on the internet the second verb being chosen presumably because it describes consuming information that takes days to digest - and our new look is designed to promote this. The wider range of contents should also help our contributors. Ever since I first read George Orwell's Why I Write ${ }^{3}$ I have been aware how apposite it is to all of us who want more than family members and carefully chosen friends to read what we put down on paper. I certainly detect Orwell's four criteria for writing in my own work and hope I am not unsettling any of our recent authors by giving further examples of Orwellian wisdom found in their contributions, and in turn illustrating how our new-look Journal satisfies the criteria also. First:

'Sheer egoism. Desire to seem clever, to be talked about, to be remembered after death, to get your own back on the grown-ups who snubbed you in childhood. It is humbug to pretend this is not a motive, and a strong one. Writers share this characteristic with scientists, artists, politicians, lawyers, soldiers, successful businessmenin short, with the whole top crust of humanity.' ${ }^{3}$ [Interestingly, Orwell does not mention doctors; he would if he were writing now.]

Of course, here Orwell is absolutely right. In a recent talk at the American Psychiatric Association, a speaker identified at least $80 \%$ of clinical psychiatric academics in the USA as satisfying the criteria for narcissistic personality disorder, so we can only thank our lucky stars that we across the pond entrust our diagnostic practice to the ICD, which, I suspect precisely for this reason, does not identify this highly prevalent condition as a formal diagnosis. Although we editors try desperately to strip the egoism from our authors, it cannot help creeping in and it is clearly a prominent factor in our editorials and correspondence. It even enters, more subtly, our original papers. So, for example, in a study entitled 'Critical developments in the assessment of personality disorder' published in one of our supplements, we find that the senior author has cited his own work in $28(27 \%)$ of the 104 references. ${ }^{4}$ What hubris, what arrogance and how much more partial can you get in an allegedly objective review? The title should have been 'Critical developments in the assessment of personality disorder: a biased and prejudiced review' and was clearly no more than an ego trip. Second:

'Aesthetic enthusiasm. Perception of beauty in the external world, or, on the other hand, in words and their right arrangement. Pleasure in the impact of one sound on another, in the firmness of good prose or the rhythm of a good story ... The 
aesthetic motive is very feeble in a lot of writers, but even a pamphleteer or writer of textbooks will have pet words and phrases which appeal to him for non-utilitarian reasons; or he may feel strongly about typography, width of margins, etc. Above the level of a railway guide, no book is quite free from aesthetic considerations. ${ }^{3}$

Can we find aesthetic enthusiasm in our Journal? Of course we can. Take, for instance, Bloch \& Green ${ }^{5}$ (quoting William Carlos Williams) ${ }^{6}$ :

'A country doctor is called by parents to attend their feverish daughter, whose condition is a cause for grave concern given the prevailing diphtheria epidemic. The child steadfastly resists the physician's efforts to examine her even attacking him when he struggles to look down her throat. After appealing unsuccessfully to the parents to take responsibility for their child's intransigence, he launches a physical tussle with the girl, convinced he must make the diagnosis. Despite recognising he had "got beyond reason", the doctor persists, because "The damned little brat must be protected against her own idiocy ... (and) others must be protected against her". He forces her mouth open, sees "both tonsils covered with membrane", and finally understands, "She had fought valiantly to keep me from knowing her secret." ' [That she has diphtheria.]

What could be better than this introduction by Bloch \& Green ${ }^{5}$ to illustrate the dilemmas posed by ethics in medicine and psychiatry? We accept that some of our other work, particularly the stringent requirements of systematic reviews, makes the entry of aesthetics more difficult. However, if we take, for example, the summary of the five types of Chinese schizophrenia - phlegm-fire; phlegm-damp; qi stagnation with blood stasis; hyperactivity of fire due to yin deficiency; and other miscellaneous types ${ }^{7}-$ we are far removed from every railway timetable, apart from the confusing one to Woking. ${ }^{8}$

The third Orwellian reason for writing is more familiar to those who frequent learned journals:

'Historical impulse. Desire to see things as they are, to find out true facts and store them up for the use of posterity. ${ }^{3}$

I would prefer 'The search for truth' rather than Orwell's title here, as one of the burning desires fuelling authors on their path to publication is to produce new evidence that contradicts the old. This is much more painful when researchers fail to replicate the findings of others and debate about the causes of the differences illustrates the Popperian view that truth is never absolute. Much of what we publish in The British Journal of Psychiatry comes under this category and also includes many negative findings when they seem to be well-founded. Thus, the failure of cognitivebehavioural therapy to prevent relapse in bipolar disorder any more than did treatment as usual when 'more than half of the patients had a recurrence by 18 months, with no significant differences between groups'9 is clearly upsetting for those who have produced opposite evidence (and may even arouse a little egoism), and we can only wait for more data before we can formulate clear conclusions.
Last, and certainly most important in Orwell's writing career: 'Political purpose. - Using the word "political" in the widest possible sense. Desire to push the world in a certain direction, to alter other peoples' idea of the kind of society that they should strive after. Once again, no book is genuinely free from political bias.'

Clearly, if we take Orwell's definition, we give voice to this desire, most recently in our efforts to improve publication rates from the current $3.7 \%$ in the less affluent countries that account for over $80 \%$ of the global population. ${ }^{10}$

What Orwell did not mention is the combination of entertainment and instruction that is behind much writing and which, I have to confess, is one of my main motivators. This is where the treats come in but, as surprise is yet another reason why people are attracted to reading, I want to keep their full nature in reserve. In any case, only Robert Howard knows exactly what they are.

Peter Tyrer, Editor, British Journal of Psychiatry, 17 Belgrave Square, London SW1X 8PG UK. Email: bjp@rcpsych.ac.uk

First received 17 November 2007, final revision 22 November 2007, accepted 22 November 2007

\section{Acknowledgements}

I thank Andrew Morris, Tom Fahy, Mike Crawford, Sukhi Shergill and Kiriakos Xenitidis, the members of the Design Committee for the Journal, for their inspired and diligent work in introducing the new format, and the staff of the Publications Department of the Royal College of Psychiatrists for making it happen.

\section{References}

1 Oldenburg H. Issue 1. Philosophical Transactions of the Royal Society 1665; 1: 1.

2 Sampson G. The death of learned journals. 2005. http://www.grsampson.net/ OnlineArts.html

3 Orwell G. Why I Write. Gangrel GB, 1946.

4 Tyrer P, Coombs N, Ibrahimi F, Mathilakath A, Bajaj P, Ranger M, Rao B, Din R. Critical developments in the assessment of personality disorder. $\mathrm{Br} J$ Psychiatry 2007; 190 (suppl 49): s51-9.

5 Bloch S, Green SA. An ethical framework for psychiatry. Br J Psychiatry 2006 188: 7-12.

6 Williams WC. The use of force. In The Doctor Stories (ed R Coles): 56-60. New Directions, 1984

7 Rathbone J, Zhang L, Zhang M, Xia J, Liu X, Yang Y, Adams CE. Chinese herbal medicine for schizophrenia: Cochrane systematic review of randomised trials. Br J Psychiatry 2007; 190: 379-84.

8 Tyrer P. From the Editor's desk: the alarm of the unexpected. Br J Psychiatry 2007; 190: 456.

9 Scott J, Paykel E, Morriss R, Bentall R, Kinderman P, Johnson T, Abbott R, Hayhurst $\mathrm{H}$. Cognitive-behavioural therapy for severe and recurrent bipolar disorders: randomised controlled trial. Br J Psychiatry 2006; 188: 313-20.

10 Patel V, Kim Y-R. Contribution of low- and middle-income countries to research published in leading general psychiatry journals, 2002-2004. Br J Psychiatry 2007; 190: 77-8. 